\title{
Evaporation Phenomenon Inside a Solar Still: From Water Surface to Humid Air
}

\author{
Amimul Ahsan 1,5, Zahangir Alam², Monzur A. Imteaz ${ }^{3}$, \\ A.B.M. Sharif Hossain ${ }^{4}$ and Abdul Halim Ghazali ${ }^{1}$ \\ ${ }^{1}$ University Putra Malaysia, Department of Civil Engineering, Faculty of Engineering, \\ 2International Islamic University Malaysia, Department of Biotechnology Engineering, \\ Faculty of Engineering, \\ ${ }^{3}$ Swinburne University of Technology, Faculty of Engineering and Industrial Science, \\ ${ }^{4}$ University of Malaya, Institute of Biological Sciences, Faculty of Science, \\ ${ }^{5}$ Green Engineering and Sustainable Technology Lab, Institute of Advanced Technology, \\ 1,2,4Malaysia \\ ${ }^{3}$ Australia
}

\section{Introduction}

Solar stills of different designs have been proposed and investigated with a view to get greater distillate output (Murase et al., 2006). Solar stills are usually classified into two categories: a single-effect type and a multi-effect type that reuses wasted latent heat from condensation (Fath, 1998; Toyama et al., 1990). The integration between a solar collector and a still is classified into passive and active stills (Tiwari \& Noor, 1996; Kumar \& Tiwari; 1998). Single-effect passive stills are composed of convectional basin, diffusion, wick and membrane types (Murase et al., 2000; Korngold et al., 1996). The varieties of a still with cover cooling (Abu-Arabi et al., 2002; Abu-Hijleh et al., 1996) and a still with a multi-effect type basin (Tanaka et al., 2000) have been studied.

A basin-type solar still is the most common among conventional solar stills (Chaibi, 2000; Nafey et al., 2000; Hongfei et al., 2002; Paul, 2002; Al-Karaghouli \& Alnaser, 2004; Tiwari \& Tiwari, 2008). A small experimental Tubular Solar Still (TSS) was constructed to determine the factors affecting the nocturnal production of solar stills (Tleimat \& Howe, 1966). Furthermore, a detailed analysis of this TSS of any dimensions for predicting its nocturnal productivity was presented (Tiwari \& Kumar, 1988). They (Tleimat \& Howe, 1966; Tiwari \& Kumar, 1988) mainly focused on the theoretical analysis of the nocturnal production of TSS. A simple transient analysis of a tubular multiwick solar still was presented by Kumar and Anand (1992). This TSS (Tleimat \& Howe, 1966; Tiwari \& Kumar, 1988; Kumar \& Anand, 1992) is made of heavy glass and cannot be made easily in remote areas. The cost of glass is quite high as well (Ahsan et al., 2010).

When water supply is cut off due to natural disasters (tsunamis, tornados, hurricanes, earthquakes, landslides, etc.) or unexpected accidents, a lightweight compact still, which is made of cheap and locally acquired materials, would be reasonable and practical. The second model of the TSS was, therefore, designed to meet these requirements and to improve some of the limitations of the basin-type still and of the TSS made of glass. Since 
the cover material (a vinyl chloride sheet) is a little heavy and cannot form into an ideal size easily (Islam, 2006; Fukuhara \& Islam, 2006; Islam et al., 2005; Islam et al., 2007a), a polythene film was adopted as a cheap new material for the cover. Consequently, the cover weight and the cost of the second model were noticeably reduced and the durability was distinctly increased. These improvements also can help to assemble and to maintenance the second model of TSS easily for sustainable use (Ahsan et al., 2010). A complete numerical analysis on TSS has been presented by Ahsan \& Fukuhara, 2008; Ahsan, 2009; Ahsan \& Fukuhara, 2009; Ahsan \& Fukuhara, 2010a, 2010b.

Many researchers (Chaibi, 2000; Clark, 1990; Cooper, 1969; Dunkle, 1961; Hongfei et al., 2002; Malik et al., 1982; Shawaqfeh \& Farid, 1995) have focused their research on conventional basin type stills rather than other types such as tubular still. Most of the heat and mass transfer models of the solar still have been described using temperature and vapor pressure on the water surface and still cover, without noting the presence of intermediate medium, i.e. humid air (Dunkle, 1961; Kumar \& Anand, 1992; Tiwari \& Kumar, 1988). Nagai et al. (2011) and Islam et al. (2007b), however, found that the relative humidity of the humid air is definitely not saturated in the daytime. Islam (2006) formulated the evaporation in the TSS based on the humid air temperature and on the relative humidity in addition to the water temperature and obtained an empirical equation of the evaporative mass transfer coefficient. Since the empirical equation does not have a theoretical background, it is still not known whether it can be used, when the trough size (width or length) is changed (Ahsan \& Fukuhara, 2008).

In this chapter, a comparison of the evaporation and distilled water production between the first model and second one is described. Additionally, this chapter aims to present the theoretical formulation of a model for the evaporation in a TSS by dimensional analysis.

\section{Production principle}

The TSS consists of a transparent tubular cover and a black semicircular trough inside the tubular cover. The solar radiant heat after transmitting through a transparent tubular cover is mostly absorbed by water in the trough. Consequently, the water is heated up and evaporates. The water vapor density of the humid air increases associated with the evaporation from the water surface and then the water vapor is condensed on the inner surface of the tubular cover, releasing its latent heat of vaporization. Finally, the condensed water naturally trickles down toward the bottom of the tubular cover due to gravity and then is stored into a collector through a pipe equipped at the lower end of the tubular cover (Ahsan et al., 2010).

\section{Overview of first model and second one}

\subsection{Structure of TSS}

Fig. 1(a) shows the cross section of the second model of the TSS. The frame was assembled with six GI pipes and six GI rings arranged in longitudinal and transverse directions, respectively. The GI pipe was $0.51 \mathrm{~m}$ in length and $6 \mathrm{~mm}$ in diameter. The GI ring was $0.38 \mathrm{~m}$ in length and $2 \mathrm{~mm}$ in diameter. The reasons for selection of GI material are light weight, cheap, available in market and commonly used in different purposes. The frame was wrapped with a tubular polythene film. The film is easily sealed by using a thermaladhesion machine (Ahsan et al., 2010). 


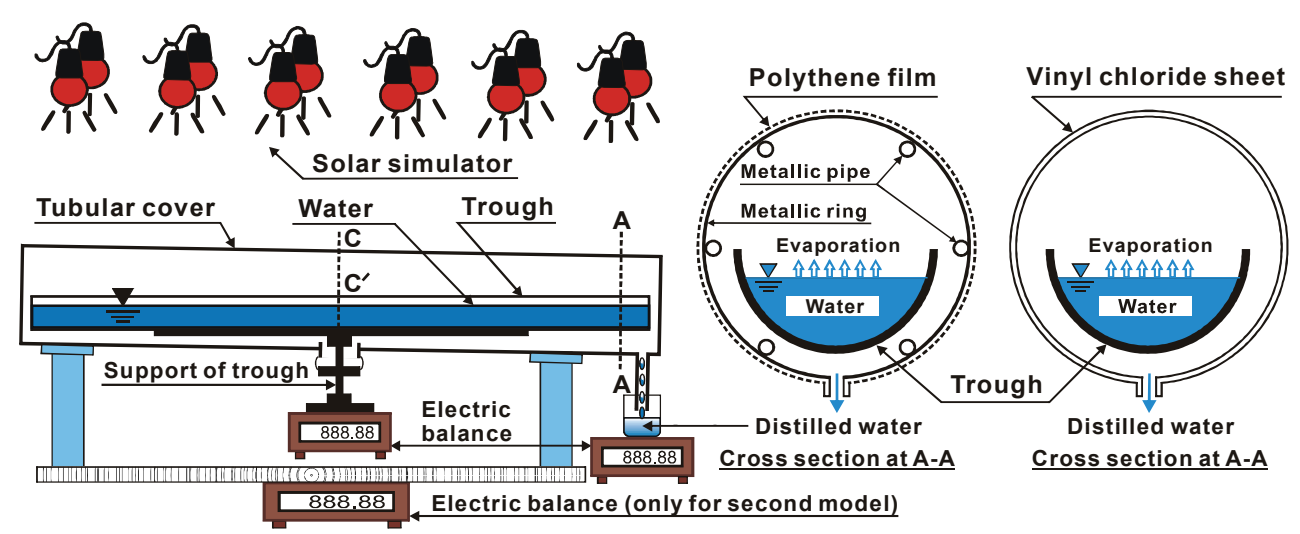

a) Second model b) First model

Fig. 1. Schematic diagram of the experiment (Ahsan et al., 2010)

The tubular cover of the first model designed by the research group was made of a transparent vinyl chloride sheet $0.5 \mathrm{~mm}$ in thickness (Fukuhara et al., 2002; Islam et al., 2004). The cross section of the first model is shown in Fig. 1(b) (Ahsan et al., 2010).

The specifications of TSS for both first and second models are summarized in Table 1. Both models have the same trough made of vinyl chloride $1.0 \mathrm{~mm}$ in thickness. Since the attached lid at the end of the tubular cover can be removed easily, the trough can be promptly taken out and inserted back after flushing the accumulated salt in the trough (Ahsan et al., 2010).

\begin{tabular}{lc}
\hline \multicolumn{1}{c}{ Parameter } & Value \\
\hline Length of tubular cover $(\mathrm{m})$ & 0.52 \\
Diameter of tubular cover $(\mathrm{m})$ & 0.13 \\
Length of trough $(\mathrm{m})$ & 0.49 \\
Diameter of trough $(\mathrm{m})$ & 0.10 \\
\hline
\end{tabular}

Table 1. Specifications of TSS for both first and second models (Ahsan et al., 2010)

An ordinary polythene film which is most common was used first as a cover for the second model of TSS. Since the durability of this ordinary polythene film was observed as about 5 months, two new durable polythene films; namely Soft Polyvinyl Chloride (SPVC) and Diastar (commercial name of the Agricultural Polyolefin Durable Film) were, therefore, chosen for practical purposes. Diastar would be preferable for a longer lifespan and is selected finally as the cover of the second model of TSS since it is guaranteed for 5 years by the manufacturer. Hence, the required maintenance frequency of the second model using Diastar is expected for 5 years, while it is about 2 years for the first one. The cover weight of the second model using Diastar was reduced to one-fifth compared to the first one. The cost of Diastar is also very cheap, i.e. about $4 \%$ of the first one. The second model is simpler, lighter, cheaper and more durable than the first one. These improvements make the assembly and maintenance of the new TSS easier (Ahsan et al., 2010). 
Proper measures should be taken for disposal of such used polythene films. In Japan, a most common technique is disposed to under soil to save and keep the environment clean.

\subsection{Cost of fresh water production using TSS}

The most important factor for the practical application of TSS is the cost of fresh water production. The fresh water production cost using the second model is about $1245 \mathrm{Yen} / \mathrm{m}^{3}$, which is only $13 \%$ of that of the first one. In Japan, the price of the materials is expensive. It is, therefore, expected that the water production cost will be reduced by one-third in developing and underdeveloped countries (Ahsan et al., 2010).

\section{Experiment 1: method, conditions and results}

\subsection{Experimental method of second model}

The experiment was carried out in a temperature and relative humidity controlled room to keep the external environmental conditions surrounding the TSS constant. The equipment consisted of a TSS, a solar simulator, a pyranometer (EKO, model: MS- $4, \pm 1 \%$ error), a data logger (MCS, model: 486TRH, $\pm 2 \%$ error), three thermo-hygrometers (VIASALA, model: HMP13, < $\pm 2 \%$ error) and three electric balances (METTLER TOREDO, model: BBK42235DLA, readability: 0.01g) connected to three computers (Ahsan et al., 2010).

The solar simulator had 12 infrared lamps $(125 \mathrm{~W})$ arranged in six rows of two lights each. In this experiment, the temperatures of the water surface $\left(T_{w}\right)$, humid air $\left(T_{h a}\right)$, tubular cover $\left(T_{c}\right)$ and ambient air $\left(T_{a}\right)$, relative humidity of the humid air $\left(R H_{h a}\right)$ and ambient air $\left(R H_{a}\right)$, and radiant heat flux $\left(R_{s}\right)$ were measured with thermocouples, thermo-hygrometers and a pyranometer, respectively. The measurements for $T_{w}, T_{h a}, T_{c}$ and $R H_{h a}$ were performed at the center of the TSS (section C-C' in Fig. 1). A thermocouple was placed in shallow water to measure $T_{w}$. Sixteen thermocouples were attached on both inner and outer surfaces of the tubular cover at eight different points at the same intervals along the circumference of the cover. The average output of these points of the inner surface was adopted as the value of $T_{c}$. A thermocouple and a thermo-hygrometer were set at $50 \mathrm{~mm}$ below the top of the tubular cover to measure $T_{h a}$ and $R H_{h a}$. The data were automatically downloaded to the data logger at one-minute intervals (Ahsan et al., 2010).

A special experimental technique to measure independently the evaporation, condensation and production of the TSS was developed. The evaporation was directly measured by placing the support frame of the trough on an electric balance, which was attached without any contact with the other components of the TSS (Fig. 1). The mass of condensation was obtained by a direct weight measurement of the TSS using a support frame on a larger electric balance. The production was directly observed by using a collector on another electric balance. The time variations of the evaporation, condensation and production were also automatically and simultaneously recorded by three computers connected to three electric balances with a minimum reading of $0.01 \mathrm{~g}$ (Ahsan et al., 2010).

\subsection{Experimental method of first model}

The same experiment using the first model was carried out in the same laboratory at the University of Fukui, Japan. There was no difference in the equipment used in the first experiment and second one except an additional electric balance to observe the 
condensation flux for the second one. The results of the first model were then compared with the results of the second experiment using the second model (Ahsan et al., 2010).

\subsection{Experimental conditions}

Table 2 summarizes the experimental conditions applied to both first and second models. The external experimental conditions were the same for both cases.

\begin{tabular}{lc}
\hline \multicolumn{1}{c}{ Parameter } & Value \\
\hline Temperature, $\mathrm{Ta}\left({ }^{\circ} \mathrm{C}\right)$ & $15 \sim 35$ \\
Relative humidity, $\mathrm{RHa}(\%)$ & 40 \\
Radiant heat flux, $\mathrm{Rs}(\mathrm{W} / \mathrm{m} 2)$ & 800 \\
Water depth $(\mathrm{mm})$ & 20 \\
Experimental duration $(\mathrm{hr})$ & 8 \\
\hline
\end{tabular}

Table 2. Experimental conditions applied to both first and second models (Ahsan et al., 2010)

\subsection{Experimental results}

Figs. 2(a) and (b) show the time variations of the hourly evaporation flux, $w_{e}$, hourly condensation flux, $w_{c}$ (for the second model only), hourly production flux, $w_{p}$, temperatures $\left(T_{w}, T_{h a}\right.$ and $\left.T_{c}\right)$ and $R H_{h a}$ for the second model and first one, respectively. The time required for a steady state of $w_{e}, w_{c}$ and $w_{p}$ was about six hours after starting both experiments. The start of the experiment designated as $t=0$ indicates the time of switching on the solar simulator (Ahsan et al., 2010).

It can be seen from Figs. 2(a) and (b) that $w_{e}$ was detected within the first hour of the experiment, while $w_{p}$ was recorded two hours after the start of the experiment. There existed a big time lag between $w_{e}$ and $w_{p}$. However, the time lag between $w_{e}$ and $w_{c}$ was very small and it was hard to distinguish the difference between them in Fig. 2(a) (Ahsan et al., 2010).

It was found that $w_{e}$ and $w_{p}$ gradually decreased in both models as $T_{a}$ fell from 35 to $15^{\circ} \mathrm{C}$. The values of $w_{e}$ and $w_{p}$ were slightly lower in the second model than in the first one under the same experimental conditions. The drop in the values of $w_{e}$ and $w_{p}$ would be a result of the difference in the design of the first model and second one. It was observed that there was an obstruction of the trickle down of the condensed water on the polythene film due to the GI pipes, horizontally arranged inside the cover of the second model as shown in Fig. 1(a). This obstruction might be the cause of less condensation and production rate for the second model of TSS (Ahsan et al., 2010).

A further important point seen in Fig. 2 is that $R H_{h a}$ was remarkably below $100 \%$ in both models, i.e. the humid air was definitely not saturated. If the vapor density of the humid air, $\rho_{v h a}$ is saturated, the evaporation condition on the water surface, i.e. $\rho_{v w}>\rho_{v h a}\left(\rho_{v w w}\right.$ : vapor density on the water surface) is not satisfied, because of $T_{h a} \geq T_{w}$ (see Fig. 2(a)) (Ahsan et al., 2010). Nagai et al. (2002) reported the same result from their experiment using a basin-type still.

Since the humid air is definitely not saturated, it is inferred that $w_{e}, w_{c}$ and $w_{p}$ would be strongly affected by the humid air temperature and relative humidity fraction, $T_{h a} / R H_{h a}$. Fig. 3 shows the relationship of $w_{e}$, $w_{c}$ and $w_{p}$ with $T_{h a} / R H_{h a}$ for the first model and second one. It is found that $w_{p} \approx w_{c} \approx w_{e}$ and these $\left(w_{e}, w_{c}\right.$ and $\left.w_{p}\right)$ were proportional to $T_{h a} / R H_{h a}$ regardless of the models (Ahsan et al., 2010). 


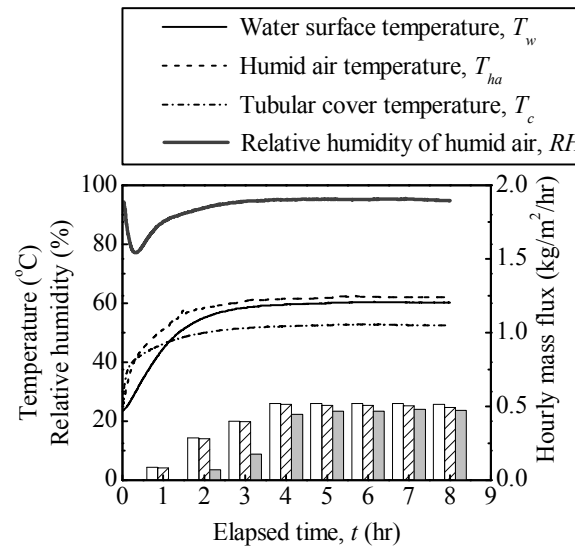

a) Second model
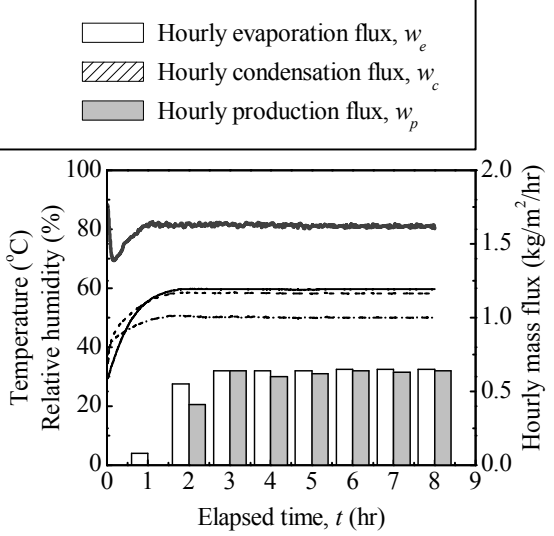

b) First model

(1) Ambient air temperature, $T_{a}=35^{\circ} \mathrm{C}$

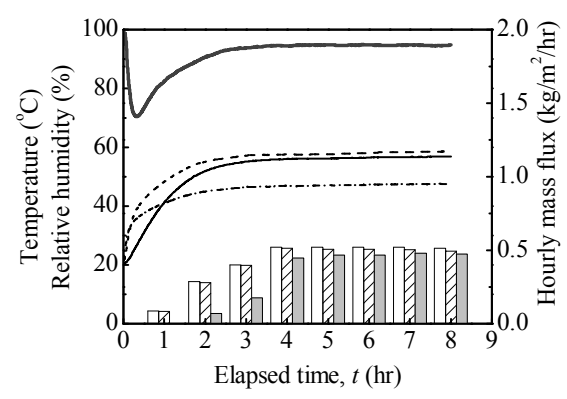

a) Second model

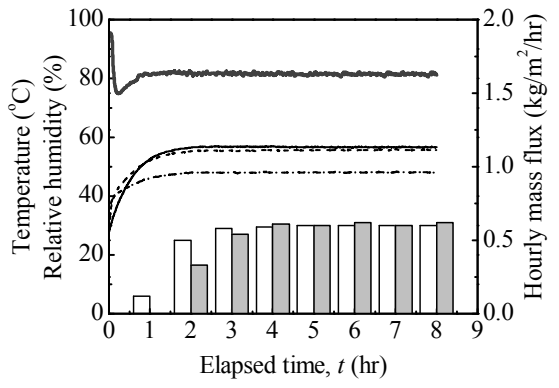

b) First model

(2) Ambient air temperature, $T_{a}=30^{\circ} \mathrm{C}$

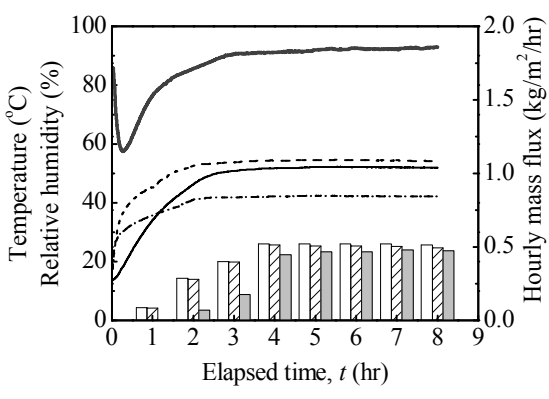

a) Second model

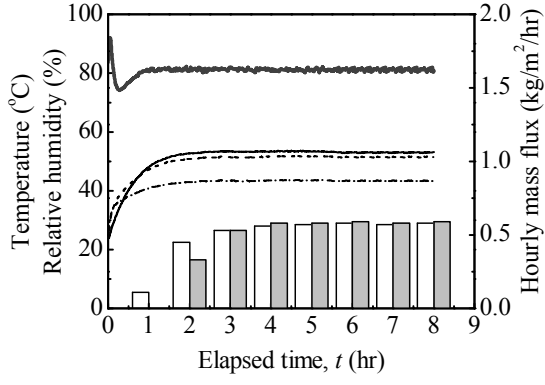

b) First model

(3) Ambient air temperature, $T_{a}=25^{\circ} \mathrm{C}$

Fig. 2. Time variations of the hourly evaporation flux, $w_{e}$, hourly production flux, $w_{p}$, temperatures $\left(T_{w}, T_{h a}\right.$ and $\left.T_{c}\right)$ and $R H_{h a}$ for different $T_{a}$ ranged from 15 to $35^{\circ} \mathrm{C}$ for the first model and second one (Ahsan et al., 2010) 


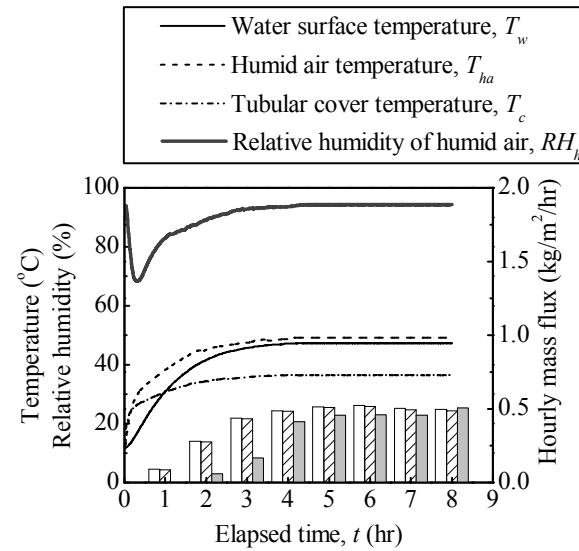

a) Second model
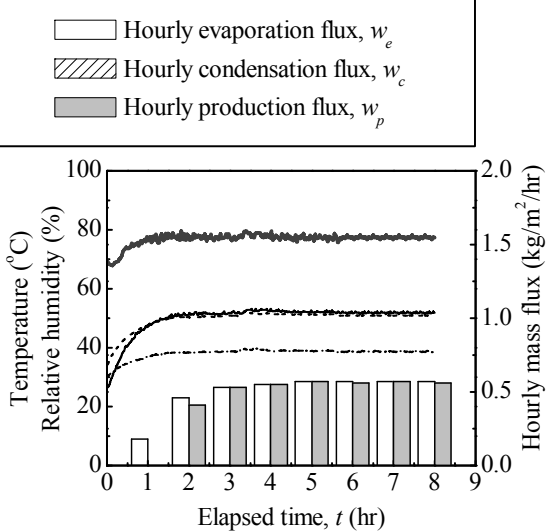

b) First model

(4) Ambient air temperature, $T_{a}=20^{\circ} \mathrm{C}$

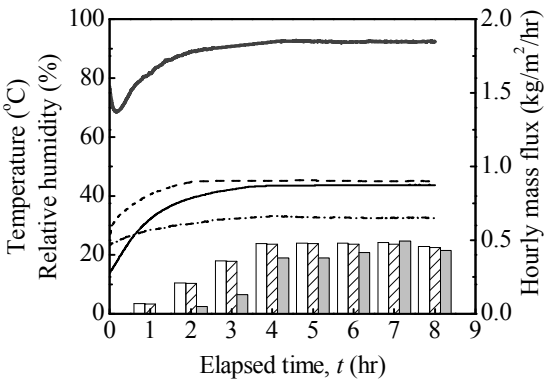

a) Second model

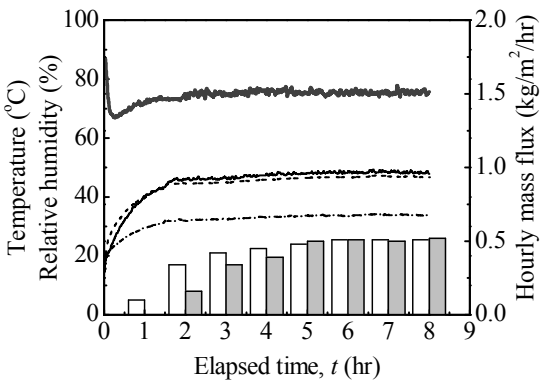

b) First model

(5) Ambient air temperature, $T_{a}=15^{\circ} \mathrm{C}$

Fig. 2. Time variations of the hourly evaporation flux, $w_{e}$, hourly production flux, $w_{p}$, temperatures $\left(T_{w}, T_{h a}\right.$ and $\left.T_{c}\right)$ and $R H_{h a}$ for different $T_{a}$ ranged from 15 to $35^{\circ} \mathrm{C}$ for the first model and second one (Ahsan et al., 2010) (continuation)

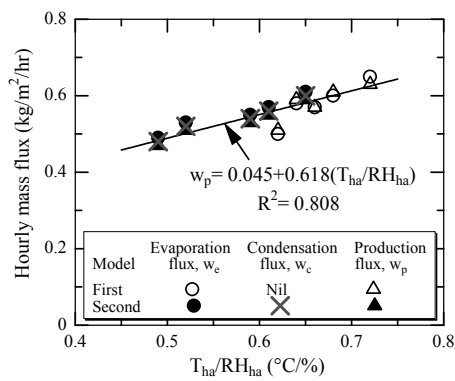

Fig. 3. Relationship between the hourly mass fluxes $\left(w_{e}, w_{c}\right.$ and $\left.w_{p}\right)$ and the humid air temperature and relative humidity fraction, $T_{h a} / R H_{h a}$, for the first model and second one (Ahsan et al., 2010) 


\section{Theory of mass transfer}

\subsection{Previous evaporation model}

Islam (2006) formulated the evaporation in the TSS based on the humid air temperature and on the relative humidity in addition to the water temperature and obtained an empirical Eq. 1 of the evaporative mass transfer coefficient $(\mathrm{m} / \mathrm{s}), h_{\text {ew }}$

$$
h_{e w}=1.37 \times 10^{-3}+5.15 \times 10^{-4}\left(T_{w}-T_{c}\right)
$$

where, $T_{w}=$ absolute temperature of the water surface; and $T_{c}=$ absolute temperature of the tubular cover.

\subsection{Purposes and research flow of present model}

The main purposes and procedures of this research are as follows:

1. Making an evaporation model with theoretical expression of $h_{e w}$

2. Verifying the validity of the evaporation model

Three steps are taken in order to attain the two purposes described above. The purpose of the first step is to determine the value of $m$ that is one of two unknown parameters in a new theoretical expression of $h_{e w}$ derived by dimensional analysis. To achieve this, the evaporation experiment in this study (present laboratory-evaporation experiment) was designed and thus the correlation between the trough width, $B$, and hourly evaporation from the whole water surface in a trough, $W$, identifies the value of $m$ (Ahsan \& Fukuhara, 2008).

The purpose of the second step is to determine the value of $a$ that is another unknown parameter in the theoretical expression of $h_{\text {ew }}$ using the previous laboratory-TSS experimental results. Consequently, the formulization of $h_{e w}$ is given in the second step and the first purpose is completed. Finally, the purpose of the third step is to verify the validity of the evaporation model with the new $h_{e w}$ formulized in the second step. Therefore, the calculated evaporation mass flux was compared with the observed data obtained from the previous field-TSS experiment. Furthermore, the calculation accuracy of the previous evaporation model and another model proposed by Ueda (2000) is examined using the same field-TSS experimental data. Thus, the second purpose is achieved (Ahsan \& Fukuhara, 2008).

\subsection{Humid air}

The density of the humid air (After Brutsaert, 1991) inside a TSS can be expressed as

$$
\rho=\frac{P_{o}}{R_{d} T_{h a}}\left(1-\frac{0.378 e_{v h a}}{P_{o}}\right)
$$

where, $P_{0}=$ total pressure of the humid air; evha $=$ partial pressure of water vapor in the humid air; Tha $=$ absolute temperature of the humid air; and $R d=$ specific gas constant of dry air. Note that $\rho=\rho d+\rho v h a$, where, $\rho d=$ density of dry air; and $\rho v h a=$ density of water vapor in the humid air. The density of the humid air on the water surface, $\rho s$, can be written as (Ahsan \& Fukuhara, 2008)

$$
\rho_{s}=\frac{P_{o}}{R_{d} T_{w}}\left(1-\frac{0.378 e_{v w}}{P_{o}}\right)
$$


where, $e_{v w}=$ saturated water vapor pressure. Similarly, $\rho_{s}=\rho_{d}+\rho_{v w}$, where, $\rho_{v w}=$ density of saturated water vapor on the water surface. From Eqs. 2 and 3, the ratio of $\rho$ to $\rho_{s}$ is given by (Ahsan \& Fukuhara, 2008)

$$
\frac{\rho}{\rho_{s}}=\frac{P_{o}-0.378 e_{v h a}}{P_{o}-0.378 e_{v w}} \cdot \frac{T_{w}}{T_{h a}}
$$

Since the following conditions, $e_{v w}>e_{v h a}$ and $T_{h a} \approx T_{w}$ are usually observed in a TSS (see Table 5), $\rho$ is greater than $\rho_{s}$. This implies that the buoyancy of air occurs on the water surface and might increase the evaporation from the water surface (Ahsan \& Fukuhara, 2008).

\subsection{Evaporation by natural convection}

We modified a diffusion equation proposed by Ueda (2000) that is applied for the evaporation from the water surface in the stagnant air with a uniform temperature. The modification of Ueda's model (present model) is attributed to the difference in the applicable condition of the diffusion equation as shown in Table 3 (Ahsan \& Fukuhara, 2008).

\begin{tabular}{|c|c|c|}
\hline & Present model & Ueda's model \\
\hline $\begin{array}{l}\text { Evaporation equation } \\
\text { (diffusion type) }\end{array}$ & $w_{x}=K_{m} \frac{e_{v w}-e_{v h a}}{\delta}$ & $w_{x}=K_{o} \frac{e_{v w}-e_{v h a}}{\delta}$ \\
\hline $\begin{array}{l}\text { Physical meaning of } \\
\text { the coefficient }\end{array}$ & $\begin{array}{c}K_{m}=\text { Dispersion due to instability of } \\
\text { humid air }\end{array}$ & $\begin{array}{c}K_{o}=\text { Diffusion due to } \\
\text { molecular motion }\end{array}$ \\
\hline \multicolumn{3}{|c|}{ Air conditions on the water surface } \\
\hline Temperature $\left({ }^{\circ} \mathrm{C}\right)$ & $\begin{array}{l}\text { Non-uniform } \\
\text { Upper part: low temperature, } \\
\text { Lower part: high temperature }\end{array}$ & Uniform \\
\hline Stability of air & Unstable & Neutral \\
\hline
\end{tabular}

Table 3. Differences between present and Ueda's model (Ahsan \& Fukuhara, 2008)

A modified diffusion equation to calculate the local evaporation mass flux, $w_{x}$, from the water surface in a trough inside a TSS is expressed as (Ahsan \& Fukuhara, 2008)

$$
w_{x}=K_{m} \frac{e_{v w}-e_{v h a}}{\delta}
$$

where, $K_{m}=$ dispersion coefficient of the water vapor; $x=$ transverse distance from the edge of the trough; and $\delta=$ effective boundary layer thickness of vapor pressure, $e_{v}$ and depends on the convection due to the movement of the humid air in a TSS. $K_{m}$ is expressed as the product of a new parameter, $a_{v}$, (Ahsan \& Fukuhara, 2008) and the diffusion coefficient of water vapor in air, $K_{o}(\mathrm{~kg} / \mathrm{m} \cdot \mathrm{s} \cdot \mathrm{Pa})$, i.e.

$$
K_{m}=\alpha_{v} K_{o}
$$

$a_{v}$ is referred to as "evaporativity" in this paper and is influenced by not only the strength of buoyancy mentioned above but also the instability of the humid air on the water surface, because the bottom boundary temperature of the humid air, $T_{w}$, is higher than the upper boundary temperature, $T_{c}$. This is the main reason why we used $K_{m}$ instead of $K_{o}$, which is expressed by the following equation (Ahsan \& Fukuhara, 2008), 


$$
K_{o}=\frac{D M_{v}}{R T_{h a}}
$$

where, $M_{v}=$ molecular weight of the water vapor; $R=$ universal gas constant; and $D=$ molecular diffusion coefficient of water vapor $\left(\mathrm{m}^{2} / \mathrm{s}\right)$ at a normal atmospheric pressure and is calculated by means of the following empirical equation (After Ueda, 2000),

$$
D=0.241 \times 10^{-4}\left(\frac{T_{h a}}{288}\right)^{1.75}
$$

Although $K_{o}$ is a function of $T_{h a}$, the change of $K_{o}$ in the range of ordinary $T_{h a}$ is small. For example, $K_{o}=1.93 \times 10^{-10} \mathrm{~kg} / \mathrm{m} \cdot \mathrm{s} \cdot \mathrm{Pa}$ for $T_{h a}=40^{\circ} \mathrm{C}$ and $2.07 \times 10^{-10} \mathrm{~kg} / \mathrm{m} \cdot \mathrm{s} \cdot \mathrm{Pa}$ for $T_{h a}=70^{\circ} \mathrm{C}$ (Ahsan \& Fukuhara, 2008).

\subsection{Dimensional analysis}

Evaporative mass transfer is generalized by empirical equations using a dimensional analysis and correlating experimental results. Assuming that the evaporation in a TSS is induced by natural convection, the relation between $\delta$ and $x$ is characterized using a local Grashof number, Gr, and the Schmidt number, Sc (Ueda, 2000; Ahsan \& Fukuhara, 2008).

$$
\frac{x}{\delta}=\frac{w_{x} x}{\alpha_{v} K_{o}\left(e_{v w}-e_{v h a}\right)}=f(G r \cdot S c)=a(G r \cdot S c)^{n}
$$

The coefficient $a$ and the power $n$ are different for convection regimes of the humid air. The values of $a$ and $n$ are varied as follows (Ahsan \& Fukuhara, 2008):

$\mathrm{a}=0.46$ and $\mathrm{n}=1 / 4$ for the laminar natural convection $\left(1<G r_{B} \cdot S_{c}<4 \times 10^{4}\right)$; and

$\mathrm{a}=0.21$ and $\mathrm{n}=1 / 3$ for the turbulent natural convection $\left(4 \times 10^{4}<G r_{B} \cdot S c\right)$.

The local Grashof number is formed as a function of $x$ :

$$
G r=\frac{g x^{3}}{v^{2}} \cdot\left|\frac{\rho-\rho_{s}}{\rho_{s}}\right|
$$

where, $g=$ gravitational acceleration; and $v=$ kinematic viscosity. The Schmidt number is denoted as

$$
S c=\frac{v}{D}
$$

The product of the Grashof number and the Schmidt number is expressed in the form

$$
G r \cdot S c=A \cdot \frac{g x^{3}}{v D}
$$

where, $A=\left|\frac{\rho}{\rho_{s}}-1\right|$. Substituting Eq. 12 into Eq. 9, $w_{x}$ is given by (Ahsan \& Fukuhara, 2008)

$$
w_{x}=a \alpha_{v} K_{o}\left(e_{v w}-e_{v h a}\right)\left[\frac{A g}{v D}\right]^{n} x^{3 n-1}
$$


The total evaporation mass per hour $(\mathrm{kg} / \mathrm{hr})$, i.e. hourly evaporation, $W$, can be obtained by integrating the local evaporation flux over the entire water surface, that is (Ahsan \& Fukuhara, 2008),

$$
W=3600 \times L \times 2 \int_{0}^{B / 2} w_{x} d x
$$

where, $B=$ width; and $L=$ length of the trough. Integrating Eq. 14 yields the following form (Ahsan \& Fukuhara, 2008):

$$
W=C \alpha K_{o} L\left[\frac{A g}{v D}\right]^{n} B^{m}\left(e_{v w}-e_{v h a}\right)
$$

where, $a\left(=a a_{v}\right)=$ evaporation coefficient; $m=3 n$; and $C=\frac{3600 \times 2^{1-m}}{m}$.

When the water temperature, $T_{w}$, is different from the cover temperature, $T_{c}$, the coefficient $A$ in Eq. 12 can be approximated by the following form (Ahsan \& Fukuhara, 2008):

$$
A=\frac{\rho-\rho_{s}}{\rho_{s}} \approx \beta\left(T_{w}-T_{c}\right)=\beta \Delta T
$$

where, $\beta=$ volumetric thermal expansion coefficient. Substituting Eq. 16 into Eq. 15, $W$ is given by (Ahsan \& Fukuhara, 2008)

$$
W=C \alpha K_{o} L\left[\frac{g \beta \Delta T}{v D}\right]^{n} B^{m}\left(e_{v w}-e_{v h a}\right)
$$

Eq. 17 can be expressed in terms of the vapor density difference using the equation of state (Ahsan \& Fukuhara, 2008),

$$
W=C \alpha K_{o} L\left[\frac{g \beta \Delta T}{v D}\right]^{n} B^{m} R_{v}\left(T_{w} \rho_{v w}-T_{h a} \rho_{v h a}\right)
$$

where, $R_{v}=$ specific gas constant of the water vapor. Taking into account of the fact, $T_{h a} \approx T_{w}$, Eq. 18 is approximated as follows (Ahsan \& Fukuhara, 2008):

$$
W=C \alpha K_{o} L\left[\frac{g \beta \Delta T}{v D}\right]^{n} B^{m} R_{v} \bar{T}\left(\rho_{v w}-\rho_{v h a}\right)
$$

where, $\bar{T}=\frac{T_{w}+T_{h a}}{2}$. Eq. 19 is transformed as (Ahsan \& Fukuhara, 2008)

$$
W=C \alpha K_{o} L\left[\frac{g \beta}{v D}\right]^{n} B^{m} R_{v} T^{*}\left(\rho_{v w}-\rho_{v h a}\right)
$$

where, $T^{*}=\bar{T} \Delta T^{n}$. 
Finally, the evaporation mass flux $\left(\mathrm{kg} / \mathrm{m}^{2} / \mathrm{s}\right), w(=W / 3600 B L)$, is calculated by the following equation (Ahsan \& Fukuhara, 2008),

$$
w=h_{e w}\left(\rho_{v w}-\rho_{v h a}\right)
$$

where, $h_{e w}$ is given by (Ahsan \& Fukuhara, 2008)

$$
h_{e w}=\frac{2^{1-m} \alpha K_{o}}{m}\left[\frac{g \beta}{v D}\right]^{n} B^{m-1} R_{v} T^{*}
$$

\subsection{Application of the present model to the present experiment}

When the vapor pressure difference, $e_{v w}-e_{v h a}, a$ and $L$ are constant, Eq. 15 can be rewritten in terms of $B$ (Ahsan \& Fukuhara, 2008),

$$
W=\eta B^{m}
$$

where, $\eta(\mathrm{kg} / \mathrm{m} / \mathrm{hr}$ ) is expressed as (Ahsan \& Fukuhara, 2008)

$$
\eta=C \alpha K_{o} L\left[\frac{A g}{v D}\right]^{n}\left(e_{v w}-e_{v h a}\right)
$$

\begin{tabular}{|c|c|c|c|c|c|}
\hline \multirow{2}{*}{$\begin{array}{l}\text { Case } \\
\text { No. }\end{array}$} & \multirow{2}{*}{$\begin{array}{l}\text { Trough length } \\
\text { L (m) }\end{array}$} & \multirow{2}{*}{$\begin{array}{c}\text { Trough width } \\
B(\mathrm{~m})\end{array}$} & \multirow{2}{*}{$\begin{array}{c}\text { Radiant heat flux } \\
R_{s}\left(\mathrm{~W} / \mathrm{m}^{2}\right)\end{array}$} & \multicolumn{2}{|c|}{ Room air conditions } \\
\hline & & & & $T_{a}\left({ }^{\circ} \mathrm{C}\right)$ & $R H_{a}(\%)$ \\
\hline 1 & \multirow{4}{*}{0.49} & 0.05 & \multirow{4}{*}{ Nil } & \multirow{4}{*}{29} & \multirow{4}{*}{21} \\
\hline 2 & & 0.10 & & & \\
\hline 3 & & 0.20 & & & \\
\hline 4 & & 0.30 & & & \\
\hline 5 & \multirow{4}{*}{1.5} & 0.05 & \multirow{4}{*}{ Nil } & \multirow{4}{*}{29} & \multirow{4}{*}{21} \\
\hline 6 & & 0.10 & & & \\
\hline 7 & & 0.20 & & & \\
\hline 8 & & 0.30 & & & \\
\hline
\end{tabular}

Note that $e_{v h a}$ in Eq. 24 is the vapor pressure of the stagnant ambient air surrounding the trough for the present evaporation experiment (Ahsan \& Fukuhara, 2008).

Table 4. Present laboratory-evaporation experimental conditions and observed steady state values (Ahsan \& Fukuhara, 2008)

\section{Experiment 2: method and conditions}

\subsection{Present evaporation experiment}

The present evaporation experiment was carried out in a temperature and relative humidity controlled room to keep $e_{v w}$ and $e_{v h a}$ constant and the same. Table 4 shows the representative factors of the experiment such as $L, B$, radiant heat flux, $R_{s}$, ambient temperature, $T_{a}$, and ambient relative humidity, $R H_{a}$. The purpose is to investigate the relationship between $W$ and $B$ and to identify the value of $m$ in Eq. 23. For this reason, we prepared eight troughs with four different widths $(0.05,0.1,0.2$ and $0.3 \mathrm{~m})$ and two different lengths $(0.49$ and $1.5 \mathrm{~m})$. 
The trough was made of a corrugated carton paper of 3.0mm in thickness and covered by a black polythene film of $0.05 \mathrm{~mm}$ in thickness. To measure the value of $W$, we prepared four electric balances with a minimum reading of $0.01 \mathrm{~g}$ and each trough was placed on each electric balance. All of the electric balances were connected to computers. In this way, $W$ was automatically and simultaneously recorded in computers at five-minute intervals. $T_{w}$ was measured with a thermocouple and was recorded in a data logger. $T_{a}$ and $R H_{a}$ were monitored by a thermo-hygrometer (Ahsan \& Fukuhara, 2008).

\begin{tabular}{cc|c|c|}
\hline Experiment & $\begin{array}{c}\text { Present evaporation } \\
\text { experiment }\end{array}$ \\
Schematic view & $\begin{array}{c}\text { Previous TSS } \\
\text { experiment }\end{array}$ \\
\hline State of evaporation & From trough in stagnant air & From trough in TSS \\
\hline Main differences in experimental conditions
\end{tabular}

Table 5. Laboratory experimental conditions of present and previous experiments (Ahsan \& Fukuhara, 2008; Islam, 2006)

\subsection{Previous TSS experiment}

The results of the previous laboratory experiment using a TSS are cited to find the properties of $a$ in Eq. 20. The TSS was comprised of a tubular cover and a black trough in it. The length and outer diameter of the tubular cover were $0.52 \mathrm{~m}$ and $0.13 \mathrm{~m}$, respectively. Evaporation was enhanced with 12 infrared lamps $(125 \mathrm{~W})$ and was controlled by changing the radiant heat (i.e. changing the height of lamp from the TSS) and the ambient air temperature (Islam, 2006).

\subsection{Differences between the present and previous experiments}

Table 5 summarizes the main differences between the present and previous experiments. The schematic views of both experiments are also drawn in Table 5. The size of the trough was changed in the present evaporation experiment, but the external environment 
surrounding the trough maintained the same conditions. On the other hand, the external conditions $\left(R_{s}\right.$ and $\left.T_{a}\right)$ were changed in the previous experiment, but the same tough size $(L=0.49 \mathrm{~m}$ and $B=0.1 \mathrm{~m})$ was used then (Ahsan \& Fukuhara, 2008).

\subsection{Previous field-TSS experiment}

In order to support the validity of the present model, the previous field experimental results are cited in this paper. The same specification of TSS was produced for both laboratory and filed experiments (Islam, 2006).

\section{Relation between $W$ and $B$}

$\mathrm{T} w$ for the eight different troughs were nearly the same (maximum difference $0.5^{\circ} \mathrm{C}$ ) and $\mathrm{Ta}$ and $\mathrm{RHa}$ were also the same $\left(29^{\circ} \mathrm{C}\right.$ and $21 \%$, respectively). Therefore, it was established that evw-evha was the same for every experimental case. Furthermore, it is assumed that the instability of air and the strength of buoyancy on the water surface might be the same for every experimental case. Therefore, we expected that a would have the same value for every experimental case and that $\eta$ is treated as a constant (Ahsan \& Fukuhara, 2008).

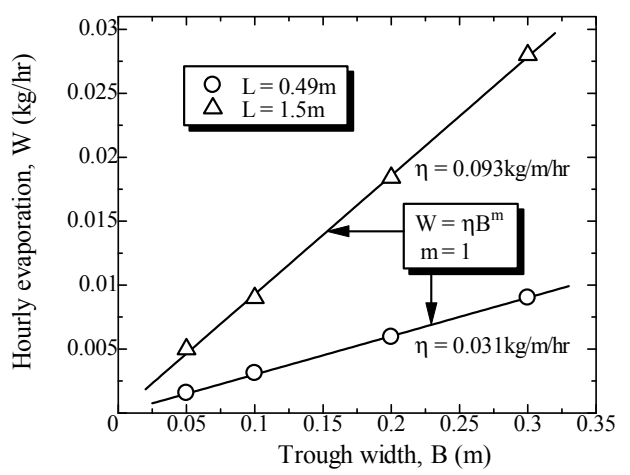

a) Relation between $W$ and $B$

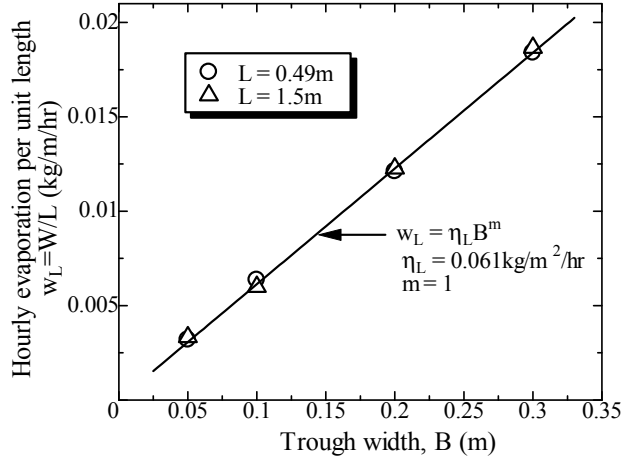

b) Relation between $w_{L}$ and $B$

Fig. 4. Variation of the hourly evaporation by changing the trough width and length (Ahsan \& Fukuhara, 2008)

The values of $G r_{B} \cdot S c\left(=A \cdot \frac{g B^{3}}{v D}\right)$ ranged from $4.03 \times 10^{4}$ to $7.70 \times 10^{6}$. The state of air flow over the trough would be, therefore, in turbulent natural convection (Ahsan \& Fukuhara, 2008). Fig. 4(a) shows the effect of the trough size $(B$ and $L)$ on $W$. $W$ is linearly proportional to $B$. We found that the value of $m$ in Eq. 23 is 1, i.e. $n=1 / 3$, regardless of $L$. $W$ for $L=1.5 \mathrm{~m}$ is nearly three times larger than that for $L=0.49 \mathrm{~m}$ for the same $B$. Consequently, the hourly evaporation per unit length, $w_{L}(=W / L)$, is expressed as a function of $B$ as shown in Fig. $4(\mathrm{~b})$ and all data is on a regression straight line; $w_{L}=\eta_{L} B^{m}$ where $\eta_{L}(=\eta / L)$ is $0.061 \mathrm{~kg} / \mathrm{m}^{2} / \mathrm{hr}$ and might be independent of $L$ for $0.49 \leq L \leq 1.5 \mathrm{~m}$ (Ahsan \& Fukuhara, 2008). The value of $m$ is 1 and is in agreement with the results of Ueda (2000).

Using $\eta_{L}=0.061 \mathrm{~kg} / \mathrm{m}^{2} / \mathrm{hr}$ and $m=1$, a can be calculated by Eq. 24 . It can be observed that the value of $a$ is a constant $(=0.06)$ for every experimental case, regardless of $B$ (Ahsan \& Fukuhara, 2008). 


\section{Evaporation coefficient}

The results of the previous laboratory-TSS experiment under twelve sets of external conditions are quoted here (Islam, 2006). Since the vapor density difference, $\rho_{v w}-\rho_{v h a}$ is different for every experimental case unlike the present evaporation experiment, $a$ should be calculated by Eq. 25 after substituting $m=1$ into Eq. 20 (Ahsan \& Fukuhara, 2008),

$$
\alpha=\frac{W}{3600 K_{o} L\left[\frac{g \beta}{v D}\right]^{\frac{1}{3}} B R_{v} T^{*}\left(\rho_{v w}-\rho_{v h a}\right)}
$$

As $G r B \cdot S c$ exceeds $4 \times 104$ for every case, it is inferred that the humid air flow on the trough in the TSS would be in turbulent natural convection state (Ahsan \& Fukuhara, 2008).

The temperature difference, $T_{w}-T_{c}$, might be one of the parameters that represent the instability of the humid air. Since $T_{w}$ is higher than $T_{c}$, it is inferred that the humid air would become unstable as the temperature difference $T_{w}-T_{c}(>0)$ increases. Based on this concept, Fig. 5 shows the relation between $T_{w}-T_{c}$ and $a$. The value of $a$ is proportional to $T_{w}-T_{c}$ and the regression can be expressed as (Ahsan \& Fukuhara, 2008)

$$
\alpha=0.123+0.012\left(T_{w}-T_{c}\right)
$$

Substituting Eq. 26 and $m=1$ into Eq. 22, $h_{\text {ew }}$ is given by (Ahsan \& Fukuhara, 2008)

$$
h_{e w}=\left[0.123+0.012\left(T_{w}-T_{c}\right)\right] \cdot\left[\frac{g \beta}{v D}\right]^{\frac{1}{3}} K_{o} R_{v} T^{*}
$$

The hourly evaporation mass flux, $w_{h}(=W / B L)$, is expressed as (Ahsan \& Fukuhara, 2008)

$$
w_{h}=3600 h_{e w}\left(\rho_{v w}-\rho_{v h a}\right)
$$

Once the four parameters $\left(T_{w}, T_{h a}, T_{c}\right.$ and $\left.R H_{h a}\right)$ are measured, $w_{h}$ can be calculated by combining Eqs. 27 and 28 (Ahsan \& Fukuhara, 2008).

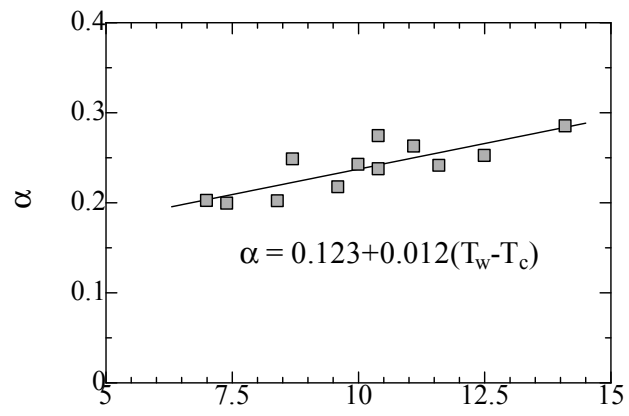

Temperature difference, $\mathrm{T}_{\mathrm{w}}-\mathrm{T}_{\mathrm{c}}\left({ }^{\circ} \mathrm{C}\right)$

Fig. 5. Relation between the evaporation coefficient, $a$, and the temperature difference, $T_{w}-T_{c}$, obtained from the previous laboratory-TSS experiment (Ahsan \& Fukuhara, 2008) 


\section{Model validation}

The applicability of the present and previous evaporation models were examined by comparing them with the previous field-TSS experimental results (Islam, 2006) obtained in Fukui, Japan (September 29 and October 6, 2005).

Fig. 6(a) and (b) show the calculation accuracy of $w_{h}$ calculated by the two models (present and previous) and Ueda's model. The accuracy of the present model is satisfactory and is applicable to both laboratory and field experiments. However, $w_{h}$ calculated by the previous model using the empirical Eq. 1 slightly underestimates the observed $w_{h}$ (Ahsan \& Fukuhara, 2008).

Ueda's model also underestimates the calculated value and the deviation from the observed value is largest among the three models. Using the coefficient $K_{o}$ related to the molecular diffusion might be the reason for such underestimation. A better estimation of $w_{h}$ could be found (Ahsan \& Fukuhara, 2008) using Ueda's model when $a_{v}\left(=K_{m} / K_{o}\right)$ is 1.14 (in average), assuming that the coefficient $a$ in Eq. 9 is 0.21 for turbulent natural convection according to Ueda (2000).

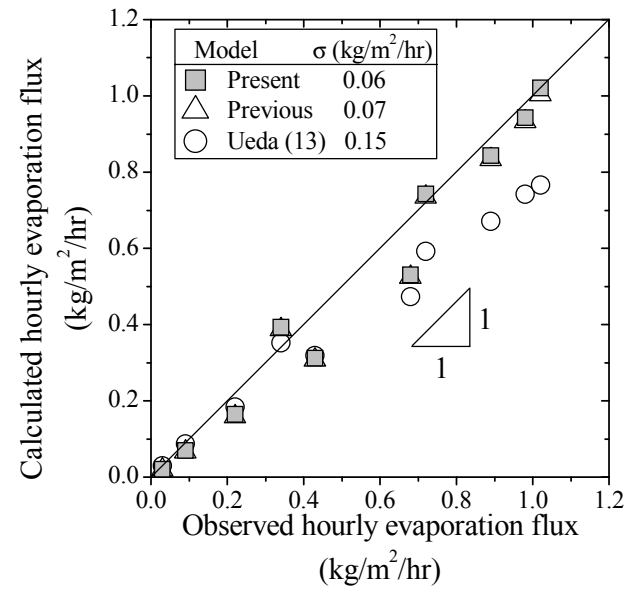

a) September 29, 2005 in Fukui, Japan

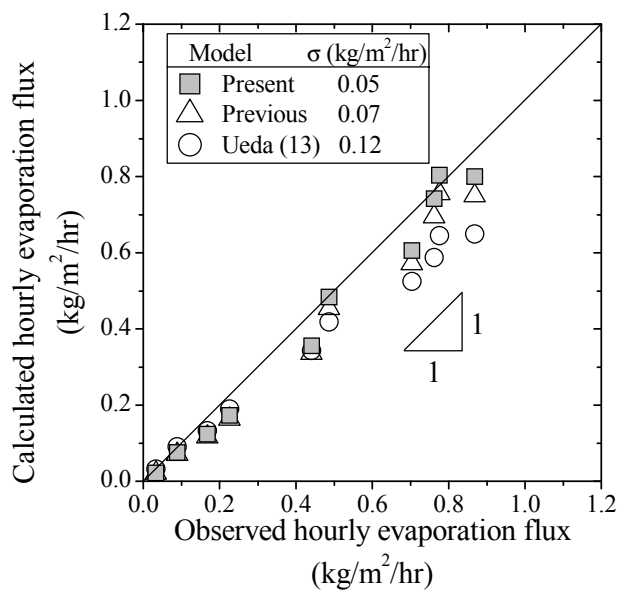

b) October 6, 2005 in Fukui, Japan

Fig. 6. Comparison of calculated hourly evaporation mass flux with the observed value of the previous field-TSS experiment (Ahsan \& Fukuhara, 2008)

The calculation accuracy of these three models was quantitatively evaluated by the root mean squared deviation, $\sigma$. That is (Ahsan \& Fukuhara, 2008),

$$
\sigma=\sqrt{\left[\frac{1}{N} \sum_{i=1}^{N}\left(w_{h o i}-w_{h c i}\right)^{2}\right]}
$$

where, $w_{\text {hoi }}=$ observed hourly evaporation mass flux; $w_{\text {hci }}=$ calculated hourly evaporation mass flux; and $N$ is the data number. The value of $\sigma$ is given for each model in Fig. 6 . The present model has the smallest $\sigma$ among the three models and the difference in $\sigma$ between two models (present and previous) is small. $\sigma$ of Ueda's model is more than twice than that of the present model (Ahsan \& Fukuhara, 2008). 


\section{Conclusion}

The cover material of the first model of the Tubular Solar Still (TSS), a transparent vinyl chloride sheet was changed to a polythene film for the second model. Thus, the second model is simpler, lighter, cheaper and more durable than the first one. These improvements make the assembly and maintenance of the new TSS easier. A special experimental technique was developed to observe the evaporation, condensation and production performance independently and simultaneously. As a result, the evaporation was detected first and then the condensation and the production followed it in turn. As for second model, the hourly evaporation and production fluxes were slightly lower than the first one under the same experimental conditions. It was revealed that the relative humidity of the humid air was definitely not saturated and the hourly evaporation, condensation and production fluxes were proportional to the humid air temperature and relative humidity fraction (Ahsan et al., 2010).

An evaporative mass transfer model was presented with a semi-theoretical expression of the evaporative mass transfer coefficient for a TSS using the dimensional analysis taking account of the humid air properties inside the still. Findings revealed from the present laboratory-evaporation experimental results that the hourly evaporation is linearly proportional to the trough width, $B$, regardless of the trough length, $L$, for $0.49 \leq L \leq 1.5 \mathrm{~m}$ (Ahsan \& Fukuhara, 2008). The movement of the humid air in the TSS belongs to turbulent natural convection state. The evaporation coefficient is proportional to the temperature difference between the water in a trough and the tubular still cover. The present model was able to reproduce the hourly evaporation mass flux obtained from the previous field-TSS experiment. It is concluded that once the four parameters (Ahsan \& Fukuhara, 2008); that is, the water temperature, humid air temperature, tubular cover temperature and the relative humidity of humid air are measured, the present model is capable of evaluating the diurnal variation of evaporation mass flux from the water surface in a trough with an arbitrary size.

\section{Acknowledgment}

Authors gratefully acknowledge Prof. Dr. Teruyuki Fukuhara, Prof. Dr. Shafiul Islam, Engr. Keiichi Waki, Engr. Hiroaki Terasaki, Dr. Akihiro Fujimoto, Dr. Yasuo Kita, Dr. Kazuo Okamura and Engr. Fumio Asano for their kind cooperation during staying in Fukui, Japan and for their continued friendly support. The partial financial support provided by the Ministry of Education, Science, and Culture of Japanese Government, Japan; Shimizu Corporation, Japan and Japan Cooperation Center, Petroleum (JCCP), Japan is also acknowledged.

\section{Nomenclature}

$\begin{array}{lll}B & = & \text { width of the trough }(\mathrm{m}) ; \\ D & = & \text { molecular diffusion coefficient of water vapor }\left(\mathrm{m}^{2} / \mathrm{s}\right) ; \\ e_{v} & = & \text { vapor pressure }(\mathrm{Pa}) ; \\ e_{v h a} & = & \text { partial pressure of water vapor in the humid air }(\mathrm{Pa}) ; \\ e_{v w} & = & \text { saturated water vapor pressure }(\mathrm{Pa}) ; \\ g & = & \text { gravitational acceleration }\left(9.807 \mathrm{~m} / \mathrm{s}^{2}\right) ; \\ G r & = & \text { Grashof number }(-) ;\end{array}$




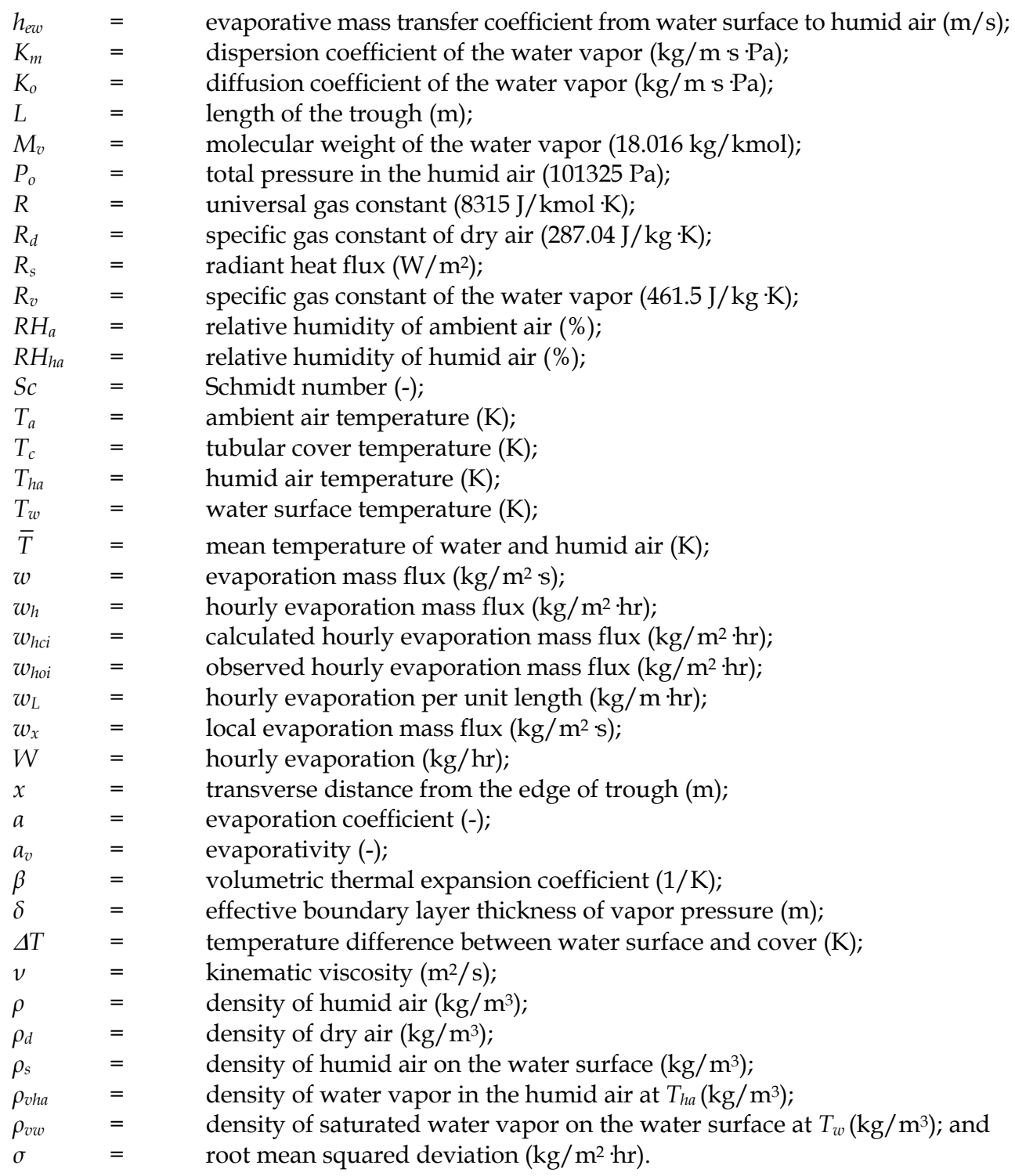

\section{References}

Ahsan, A. \& Fukuhara, T. (2008). Evaporative Mass Transfer in Tubular Solar Still. J. Hydroscience and Hydraulic Engineering, JSCE, vol. 26(2), 15-25.

Ahsan, A. (2009). Production model of new tubular solar still and its productivity characteristics. PhD thesis, University of Fukui, Japan, pp 45-73. 
Ahsan, A. \& Fukuhara, T. (2009). Condensation mass transfer in unsaturated humid air inside tubular solar still. Annual J. of Hydraulic Engineering, JSCE, vol. 53, 97-102.

Ahsan, A. \& Fukuhara, T. (2010a). Mass and Heat Transfer Model of Tubular Solar Still. Solar Energy, vol. 84 (7), 1147-1156.

Ahsan, A. \& Fukuhara, T. (2010b). Condensation Mass Transfer in Unsaturated Humid Air inside Tubular Solar Still. J. Hydroscience and Hydraulic Engineering, JSCE, vol. 28(1), $31-42$.

Ahsan, A.; Islam K.M.S.; Fukuhara, T. \& Ghazali, A.H. (2010). Experimental Study on Evaporation, Condensation and Production of a New Tubular Solar Still. Desalination, vol. 260 (1-3), 172-179.

Abu-Arabi, M.; Zurigat, Y.; Al-Hinai, H. \& Al-Hiddabi, S. (2002). Modeling and performance analysis of a solar desalination unit with double-glass cover cooling. Desalination, 143, 173-182.

Abu-Hijleh, B.A.K. (1996). Enhanced solar still performance using water film cooling of the glass. Desalination, 107, 235-244.

Al-Karaghouli, A.A. \& Alnaser, W.E. (2004). Performances of single and double basin solarstills. Applied Energy, 78, 347-354.

Brutsaert, W. (1991). Evaporation into the atmosphere, Kluwer Academic Publishers, Netherlands, pp. 37-56.

Chaibi, M.T. (2000). Analysis by simulation of a solar still integrated in a greenhouse roof, Desalination, Vol.128, pp. 123-138.

Clark, J.A. (1990). The steady-state performance of a solar still, Solar Energy, Vol.44, No.1, pp. 43-49.

Cooper, P.I. (1969). Digital simulation of transient solar still processes, Solar Energy, Vol.12, pp. 313-331.

Dunkle, R.V. (1961). Solar Water Distillation: The roof type still and a multiple effect diffusion still, Proc. international heat transfer, ASME, University of Colorado, pp. 895-902.

Fath, H.E.S. (1998). Solar desalination: a promising alternative for water provision with free energy, simple technology and a clean environment. Desalination, 116, 45-56.

Fukuhara, T.; Asano, F.; Mutawa, H.A.A.; Nagai N. \& Ito, Y. (2002). Production mechanism and performance of tubular solar still. Proc. IDA World Congress, Manama, Bahrain, March 8-13, BAH03-085.

Fukuhara, T. \& Islam, K.M.S. (2006).Tubular solar desalination and improvement of soil moisture retention by date palm. In Arid Land Hydrogeology: In Search of a Solution to a Threatened Resource. Mohamed, A. M. O.; Ed.; Taylor and Francis, London, pp. 153-162.

Hongfei, Z.; Xiaoyan, Z.; Jing, Z. \& Yuyuan, W. (2002). A group of improved heat and mass transfer correlations in solar stills, Energy Conversion and Management, Vol.43, pp. 2469-2478.

Islam, K.M.S.; Fukuhara, T. \& Asano, F. (2004). Mass transfer in Tubular Solar Still. Proc. 59th Annual Conference, JSCE, Nagoya, Japan, September 8-10, pp. 236-237.

Islam, K.M.S.; Fukuhara, T.; Asano, F. \& Mutawa, H.A.A. (2005). Productivity of the tubular solar still in the United Arab Emirates. Proc. of MTERM International Conference, Bangkok, Thailand, June 8-10, pp. 367-372. 
Islam, K.M.S. (2006). Heat and vapor transfer in tubular solar still and its production performance, PhD thesis, Department of Architecture and Civil Engineering, University of Fukui, Japan, pp. 33-52.

Islam, K.M.S.; Fukuhara, T. \& Ahsan, A. (2007a). New Analysis of a tubular solar still, Proc. IDA World Congress, Spain, CD-ROM, IDAWC/MP07-041, pp. 1-12.

Islam, K.M.S.; Fukuhara, T. \& Ahsan, A. (2007b). Tubular solar still-an alternative small scale fresh water management, Proc. international conference on water and flood management (ICWFM-2007), Bangladesh, pp. 291-298.

Kumar, A. \& Anand, J.D. (1992). Modelling and performance of a tubular multiwick solar still, Solar Energy, Vol.17, No.11, pp. 1067-1071.

Kumar, S. \& Tiwari, G.N. (1998). Optimization of collector and basin areas for a higher yield for active solar stills. Desalination, 116, 1-9.

Korngold, E.; Korin E. \& Ladizhensky, I. (1996). Water desalination by pervaporation with hollow fiber membranes. Desalination, 107, 1221-1229.

Malik, M.A.S.; Tiwari, G.N.; Kumar, A. \& Sodha, M.S. (1982). Solar Distillation: A practical study of a wide range of stills and their optimum design, construction and performance, Pergamon Press, Oxford, England, pp. 11-13.

Murase, K.; Tobataa, H.; Ishikawaa, M. \& Toyama, S. (2006). Experimental and numerical analysis of a tube-type networked solar still for desert technology. Desalination, 190, 137-146.

Murase, K.; Komiyama, S.; Ikeya, A. \& Furukawa, Y. (2000). Development of multi-effect membrane solar distillatory. Society of Sea Water Science, 54, 30-35.

Nafey, A.S.; Abdelkader, M.; Abdelmotalip, A. \& Mabrouk, A.A. (2000). Parameters affecting solar still productivity. Energy Con. \& Mang., 41, 1797-1809.

Nagai, N.; Takeuchi, M.; Masuda, S.; Yamagata, J.; Fukuhara, T. \& Takano, Y. (2002). Heat transfer modeling and field test on basin-type solar distillation device, Proc. IDA World Congress, Bahrain, CD-ROM, Bah03-072.

Shawaqfeh, A.T. \& Farid, M.M. (1995). New development in the theory of heat and mass transfer in solar stills, Solar Energy, Vol.55, No.6, pp. 527-535.

Tanaka, H.; Nosoko, T. \& Nagata, T. (2000). A highly productive basin-type-multi-effect coupled solar still. Desalination, 130, 279-293.

Paul, I.D. (2002). New model of a basin-type solar still. J. Solar Energy Eng., ASME, 124, 311314.

Tiwari, G.N. \& Kumar, A. (1988). Nocturnal water production by tubular solar stills using waste heat to preheat brine, Desalination, Vol.69, pp. 309-318.

Tiwari, G.N. \& Tiwari, A.K. (2008). Solar Distillation Practice For Water Desalination Systems. Anshan Limited, UK.

Tleimat, B.W. \& Howe, E.D. (1966). Nocturnal production of solar distillers. Solar Energy, 10, 61-66.

Toyama, S.; Nakamura, M.; Murase, K. \& Salah, H.M. (1990). Studies of desalting solar stills. Memories of the Faculty of Engineering, Nagoya University, Japan, 43, 1-53.

Tiwari, G.N. \& Noor, M.A. (1996). Characterization of solar stills. Int. J. Solar Energy, 18, 147171.

Ueda, M. (2000). Humidity and evaporation, Corona Publishing Co. Ltd., Japan, pp. 83-101. 


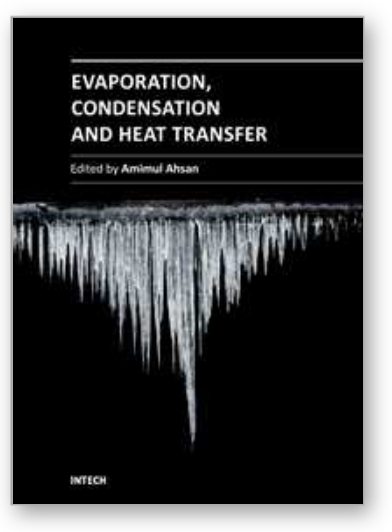

\author{
Evaporation, Condensation and Heat transfer \\ Edited by Dr. Amimul Ahsan
}

ISBN 978-953-307-583-9

Hard cover, 582 pages

Publisher InTech

Published online 12, September, 2011

Published in print edition September, 2011

The theoretical analysis and modeling of heat and mass transfer rates produced in evaporation and condensation processes are significant issues in a design of wide range of industrial processes and devices. This book includes 25 advanced and revised contributions, and it covers mainly (1) evaporation and boiling, (2) condensation and cooling, (3) heat transfer and exchanger, and (4) fluid and flow. The readers of this book will appreciate the current issues of modeling on evaporation, water vapor condensation, heat transfer and exchanger, and on fluid flow in different aspects. The approaches would be applicable in various industrial purposes as well. The advanced idea and information described here will be fruitful for the readers to find a sustainable solution in an industrialized society.

\title{
How to reference
}

In order to correctly reference this scholarly work, feel free to copy and paste the following:

Amimul Ahsan, Zahangir Alam, Monzur A. Imteaz, A.B.M. Sharif Hossain and Abdul Halim Ghazali (2011). Evaporation Phenomenon Inside a Solar Still: From Water Surface to Humid Air, Evaporation, Condensation and Heat transfer, Dr. Amimul Ahsan (Ed.), ISBN: 978-953-307-583-9, InTech, Available from: http://www.intechopen.com/books/evaporation-condensation-and-heat-transfer/evaporation-phenomenoninside-a-solar-still-from-water-surface-to-humid-air

\section{INTECH}

open science | open minds

\author{
InTech Europe \\ University Campus STeP Ri \\ Slavka Krautzeka 83/A \\ 51000 Rijeka, Croatia \\ Phone: +385 (51) 770447 \\ Fax: +385 (51) 686166 \\ www.intechopen.com
}

\author{
InTech China \\ Unit 405, Office Block, Hotel Equatorial Shanghai \\ No.65, Yan An Road (West), Shanghai, 200040, China \\ 中国上海市延安西路65号上海国际贵都大饭店办公楼 405 单元 \\ Phone: +86-21-62489820 \\ Fax: +86-21-62489821
}


(C) 2011 The Author(s). Licensee IntechOpen. This chapter is distributed under the terms of the Creative Commons Attribution-NonCommercialShareAlike-3.0 License, which permits use, distribution and reproduction for non-commercial purposes, provided the original is properly cited and derivative works building on this content are distributed under the same license. 